\title{
Grafting Carbon Nanotubes on Glass Fiber by Dip Coating Technique to Enhance Tensile and Interfacial Shear Strength
}

\author{
Bahador Dastorian Jamnani, ${ }^{1}$ Soraya Hosseini, ${ }^{2}$ Saeed Rahmanian, ${ }^{1}$ \\ Suraya Abdul Rashid, ${ }^{2,3}$ Sa'ari b. Mustapha, ${ }^{2}$ and Sepideh Keshan Balavandy ${ }^{3}$ \\ ${ }^{1}$ Department of Mechanical and Manufacturing Engineering, Faculty of Engineering, Universiti Putra Malaysia, \\ 43400 Serdang, Selangor, Malaysia \\ ${ }^{2}$ Department of Chemical and Environmental Engineering, Faculty of Engineering, Universiti Putra Malaysia, \\ 43400 Serdang, Selangor, Malaysia \\ ${ }^{3}$ Advanced Materials and Nanotechnology Lab, Institute of Advanced Technology, Universiti Putra Malaysia, \\ 43400 Serdang, Selangor, Malaysia
}

Correspondence should be addressed to Suraya Abdul Rashid; suraya_ar@upm.edu.my

Received 10 June 2015; Accepted 17 August 2015

Academic Editor: Shuping Xu

Copyright (C) 2015 Bahador Dastorian Jamnani et al. This is an open access article distributed under the Creative Commons Attribution License, which permits unrestricted use, distribution, and reproduction in any medium, provided the original work is properly cited.

\begin{abstract}
The effects of noncovalent bonding and mechanical interlocking of carbon nanotubes (CNT) coating on tensile and interfacial strength of glass fiber were investigated. CNT were coated over glass fiber by a simple dip coating method. Acid treated CNT were suspended in isopropanol solution containing Nafion as binding agent. To achieve uniform distribution of CNT over the glass fiber, an optimized dispersion process was developed by two parameters: CNT concentration and soaking time. CNT concentration was varied from 0.4 to $2 \mathrm{mg} / \mathrm{mL}$ and soaking time was varied from 1 to $180 \mathrm{~min}$. The provided micrographs demonstrated appropriate coating of CNT on glass fiber by use of CNT-Nafion mixture. The effects of CNT concentration and soaking time on coating layer were studied by performing single fiber tensile test and pull-out test. The obtained results showed that the optimum CNT concentration and soaking time were $1 \mathrm{mg} / \mathrm{mL}$ and $60 \mathrm{~min}$, respectively, which led to significant improvement of tensile strength and interfacial shear stress. It was found that, at other concentrations and soaking times, CNT agglomeration or acutely curly tubes appeared over the fiber surface which caused a reduction of nanotubes interaction on the glass fiber.
\end{abstract}

\section{Introduction}

Carbon nanotubes, both single walled and multiwalled, are widely used and well characterized as nanofillers [1]. These materials composed of graphitic sheets that are rolled into tubes possess unique properties, mainly due to their $\mathrm{sp}^{2}$ bonds [2]. The tensile strength of carbon nanotubes is about one hundred times higher than that of steel, while their specific weight is about six times lower [3]. Thus, CNT have attracted extensive investigations in the field of biomedical materials, biosensors, drug delivery, composite materials, and tissue engineering because of their high chemical stability, good mechanical and thermal properties, electrical property, and biochemical property [4]. CNT are considered as promising nanofillers in composite materials [5] which are being increasingly used in many engineering applications because of their numerous advantages over conventional engineering materials such as metals [6]. High stiffness and strength to weight ratio are among their most appealing advantages [7]. Fiber-reinforced composite (FRC) materials consist of a stiff and strong phase (fibrous filler) and another typically weaker phase (matrix). It is important to understand the drawbacks of conventional FRC materials in terms of their response to different types of mechanical loading and failure mechanisms in order to target specific areas and make progress towards the improvement of the material $[8,9]$. Failure can be manifested in many forms such as the breaking of fibers, microcracking of matrix, and separation of fibers from the matrix (debonding) [10]. 
TABLE 1: Characteristics of neat epoxy.

\begin{tabular}{|c|c|c|c|c|c|}
\hline Hardener type & $\begin{array}{l}\text { Mix ratio } \\
\text { by volume }\end{array}$ & $\begin{array}{l}\text { Mixed viscosity } \\
\text { CPS }\end{array}$ & $\begin{array}{l}\text { Ultimate tensile } \\
\text { strength }(\mathrm{MPa})\end{array}$ & $\begin{array}{l}\text { Tensile modulus } \\
\qquad(\mathrm{GPa})\end{array}$ & $\begin{array}{l}\text { Heat deflection } \\
\text { temp. }\left({ }^{\circ} \mathrm{C}\right)\end{array}$ \\
\hline 4,40 & & & & & \\
\hline $\begin{array}{l}\text { Methylenebis(cyclohexylamine) } \\
\text { and polypropylene triamine }\end{array}$ & $3: 1$ & 650 & 55 & 1.75 & 53 \\
\hline
\end{tabular}

Glass fiber (GF) is widely used as reinforcement in the manufacture of FRC materials with polymeric matrices [11] such as polyester, vinylester, phenolic, and epoxy resins [12]. However the stress transfer from the matrix to the GFs often presents a challenge to exploit the reinforcement role of fibers completely. CNT coating on GF can be suggested as an appropriate method to improve the adhesion of fiber and matrix $[13,14]$. Furthermore, the addition of the conductive CNT fiber to the nonconductive GF composite can enhance its multifunction ability for the structural health monitoring of the composite material. In addition, the CNT integration with optical fiber has been reported to improvement the sensitivity of electrochemical sensors [15]. Various researches have been done to coat CNT on carbon fiber by use of chemical vapor deposition (CVD) $[16,17]$ or electrophoretic methods [18] with much success. But GF cannot be easily used in CVD or electrophoretic deposition because of their thermal instability and nonconductive behavior, respectively [19]. Therefore, solution dip coating method [20] is considered as a suitable alternative method to coat CNT on GF. Indeed different parameters such as solvent media, filler concentration, and coating time are important factors in order to provide effective coverage of nanotubes on GF.

In this paper the effects of mechanical interlocking and noncovalent bonding of CNT on the interfacial and tensile strength of GF were investigated. A simple dip coating method is presented to graft CNT on GF by use of a binding agent. CNT suspension containing Nafion was examined with different concentrations and soaking times to find the optimal coating condition. SEM images were used to identify the CNT morphology deposited on the surface of GFs. The effects of nanotubes coverage on mechanical properties of GFs were demonstrated by performing single fiber tensile and pull-out tests. By comparing the SEM images and mechanical properties, a relationship between CNT coating and tensile and interfacial characteristics of GF was interpreted.

\section{Experimental}

2.1. Materials. All chemicals used were of analytical reagent grade purchased from Sigma Aldrich. Isopropanol was purchased from Bischem Co. Nafion solution (5\%) was obtained from High Tech Company. CNT with a diameter of 20$40 \mathrm{~nm}$ were provided by Hangzhou Dayang Chem Co. GF (obtained from Fibreglass Enterprise, China) with a diameter of $20 \mu \mathrm{m}$ was used as received. The thermoset matrix used was a commercially available epoxy resin as known as EpoxAmite purchased from Smooth-On, Inc. The thermoset was fabricated based on two epoxy and hardener components. The optimum weight ratio of epoxy and hardener was suggested by the manufacturer as $100 / 28.4$ by weight. The characteristics of neat epoxy and hardener are summarized in Table 1.

2.2. CNT-Solvent Mixture for Coating. CNT were oxidized in order to add oxygen functional groups to the carbon surface using nitric acid and sulfuric acid. $5 \mathrm{~g}$ of CNT was fluxed in $250 \mathrm{~mL}$ solution containing concentrated $\mathrm{HNO}_{3}$ (63 wt\%) and $\mathrm{H}_{2} \mathrm{SO}_{4}(98 \%)$ at $130^{\circ} \mathrm{C}$ for $2 \mathrm{~h}$ to remove impurities. The detailed procedure for the functionalization process can be found in [21]. After acid treatment, the mixture was allowed to cool. The mixture was then filtrated by using glass filter funnels via vacuum filtration. The residual was washed several times with hot distilled water to remove excess acid solution until the $\mathrm{pH}$ reached 7 [22]. Then, the acid modified CNT were dried at $100^{\circ} \mathrm{C}$ for $24 \mathrm{~h}$. The acid modified CNT were denoted as CNT-treated. The treated CNT were added to $24 \mathrm{~mL}$ isopropanol (IPA) solvent and $1 \mathrm{~mL}$ Nafion solution (5\%). Nafion (5\%) allows better dispersion of the nanotubes as it facilitates dispersion through the application of ultrasonic forces, high shear mixing, or other dispersion methods. Ultrasonication process was employed for $1 \mathrm{~h}$ to provide a homogeneous suspension. Then, the homogeneous suspension was used in order to coat GF. Different amounts of treated CNT $(0.01,0.025,0.04$, and $0.05 \mathrm{~g})$ were used to prepare coating solution. After finding the optimal CNT concentration, the GF was dip-coated on the suspension with soaking times of $1,30,60,120$, and $180 \mathrm{~min}$. The samples were dried in a vacuum oven at $70^{\circ} \mathrm{C}$ for $24 \mathrm{~h}$. The morphology of the composites was examined by scanning electron microscopy (SEM, S-4800, Hitachi).

2.3. Single Fiber Tensile Test. The tensile strength of each single GF was evaluated using a Universal Testing Machine (Instron) aiming at determining the influence of the CNT coating on the axial properties. To prepare the sample for the test, single GFs were stuck onto a paper frame with glue for better handling. Then, the fiber and frame were subjected to mechanical loading at a crosshead speed of $0.5 \mathrm{~mm} / \mathrm{min}$ [20]. The data of force and displacement were measured during the tests and used to calculate the modulus and ultimate tensile strength of specimens. In addition, the fiber diameter was measured individually by use of an optical microscope. The gauge lengths were $25 \mathrm{~mm}$. A minimum of twenty measurements were carried out for each type of coated GF specimen with fixed gauge length.

2.4. Single Fiber Pull-Out Test. Single fiber pull-out tests were carried out on a universal testing machine with the apparatus as illustrated in Figure 1. First, few drops of epoxy were put on the single fiber to be cured. A GF was pulled out at a crosshead 


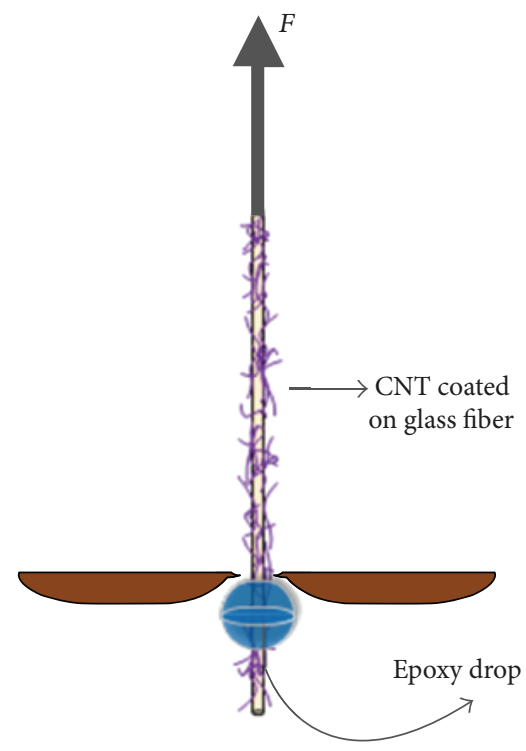

FIGURE 1: Schematic representation of single fiber pull-out test.

speed of $0.5 \mu \mathrm{m} / \mathrm{s}$ [23] from the drop of cured epoxy. The interfacial shear strength (IFSS) was calculated according to the maximum force applied to pull the GF out of the epoxy drop by the employment of the following equation:

$$
\tau_{\mathrm{IFSS}}=\frac{F_{\max }}{\pi \cdot d_{f} \cdot l_{e}},
$$

where $F_{\max }$ is defined as the maximum pullout force, $d_{f}$ is the diameter of GF, and $l_{e}$ refers to the embedded length of microdroplet. At least 20 specimens were tested for each set of single fibers.

\section{Results and Discussion}

Figure 2 shows the surface morphology of the as-prepared samples. SEM results were carried out to examine the coated surfaces and monitor the failure mechanism. Figure 2(a) shows an SEM image of the neat GF and Figures 2(b), 2(c), and 2(d) show various concentrations of CNT coated on the GF using a set soaking time of $1 \mathrm{~min}$.

The surface of neat GF was smooth in nature while the coating with $0.4 \mathrm{mg} / \mathrm{mL}$ CNT concentration showed a thin and nonuniform coating on the GF surface. As shown in Figure 2(c), increasing the suspension concentration to $1 \mathrm{mg} / \mathrm{mL}$ led to a relatively uniform and denser deposition of nanotubes on the fiber surface. The inset image also provides better view of the CNT configuration at high magnification which shows individual attachment of nanotubes. Figure 2(d) reveals a high density attachment of CNT with agglomerated regions which were formed by soaking fibers in $2 \mathrm{mg} / \mathrm{mL}$ suspension concentration. The SEM images shown in Figure 2 qualitatively indicate that $1 \mathrm{mg} / \mathrm{mL}$ is the optimal concentration which provides an appropriate amount of CNT coating on GF. Therefore, this concentration was selected to examine the effect of soaking time on coating morphology.
The results of soaking time are shown in Figures 3(a) and 3(b) with soaking times of 60 and $180 \mathrm{~min}$, respectively. In comparison to $5 \mathrm{~min}$ soaking time Figure 2(c) and Figure 3(a) show a homogeneous and complete coverage of nanotubes on the fiber surface, which demonstrate the coating improvement with 60 min soaking time. Soaking the GF for a longer time especially at $180 \mathrm{~min}$ resulted in higher absorption of nanotubes to the surface. In this situation, the larger coating thickness of CNT and the interaction among nanotubes separate them in some region from GF. It can be interpreted that the adhesion of CNT to the fiber surface was declined because of stronger interaction between nanotubes and formation of bulk aggregations. By comparing the SEM images of Figures 2 and 3, it can be deduced that both CNT concentration and soaking time are important factors to consider in order to obtain proper grafting of nanotubes on to the fiber surface.

Single fiber tensile tests were carried out to measure the effect of CNT coating on the modulus and tensile strength of GF. The tensile properties of as-received and coated GF are presented in Figures 4(a) and 4(b). Comparing the elastic modulus of coated GF in Figure 4(a) reveals that the CNT coating does not influence elastic modulus significantly. However, the CNT coating affected the ultimate tensile strength of GF under certain treatment conditions. Varying the concentration of CNT suspension revealed that an optimum coating concentration was achieved at $1 \mathrm{mg} / \mathrm{mL}$ CNT suspension which yielded an enhancement of tensile strength by $28 \%$. Lower or higher CNT coating concentrations improved the tensile strength of GF only slightly. Interestingly coating the GF with the highest concentration of $2 \mathrm{mg} / \mathrm{mL}$ led to a strength similar to the neat GF. This implies that the CNT coating with higher concentration somehow does not interact with the surface of GF effectively. Perhaps a thicker coating led to some debonding of the coating from the surface of the fiber.

After detection of optimum concentration of CNT suspension, the effect of GF soaking time on the tensile strength of the GF was also studied as shown in Figure 4(b). The results show that a similar trend was achieved for soaking time whereas an optimum soaking time was observed. The tensile strength increased by $38 \%$ as the soaking time was increased to $1 \mathrm{~h}$. However, extending the soaking time for more than 1 hour led to a decrease in the tensile strength. Indeed, higher soaking time resulted in a higher density of coated nanotubes on the GF surface which can explain the change of single fiber strength by debonding process.

The IFSS was also studied as shown in Figures 5(a) and 5(b). The IFSS increased to $76 \%$ compared to neat fiber by increasing the CNT concentration to $1 \mathrm{mg} / \mathrm{mL}$. However, increasing the concentration further led to a decrease in IFSS. As for the effect of soaking time, increasing the soaking time to $1 \mathrm{~h}$ led to an improvement by $23 \%$ in comparison to 1 min soaking time and by $116 \%$ in comparison to neat GF. Extending the soaking time further led to a decrease in IFSS of coated GF.

Looking at the obtained mechanical properties hints that CNT coating affects the strength and IFSS of single fiber, which is related to the surface properties of the fibers. 

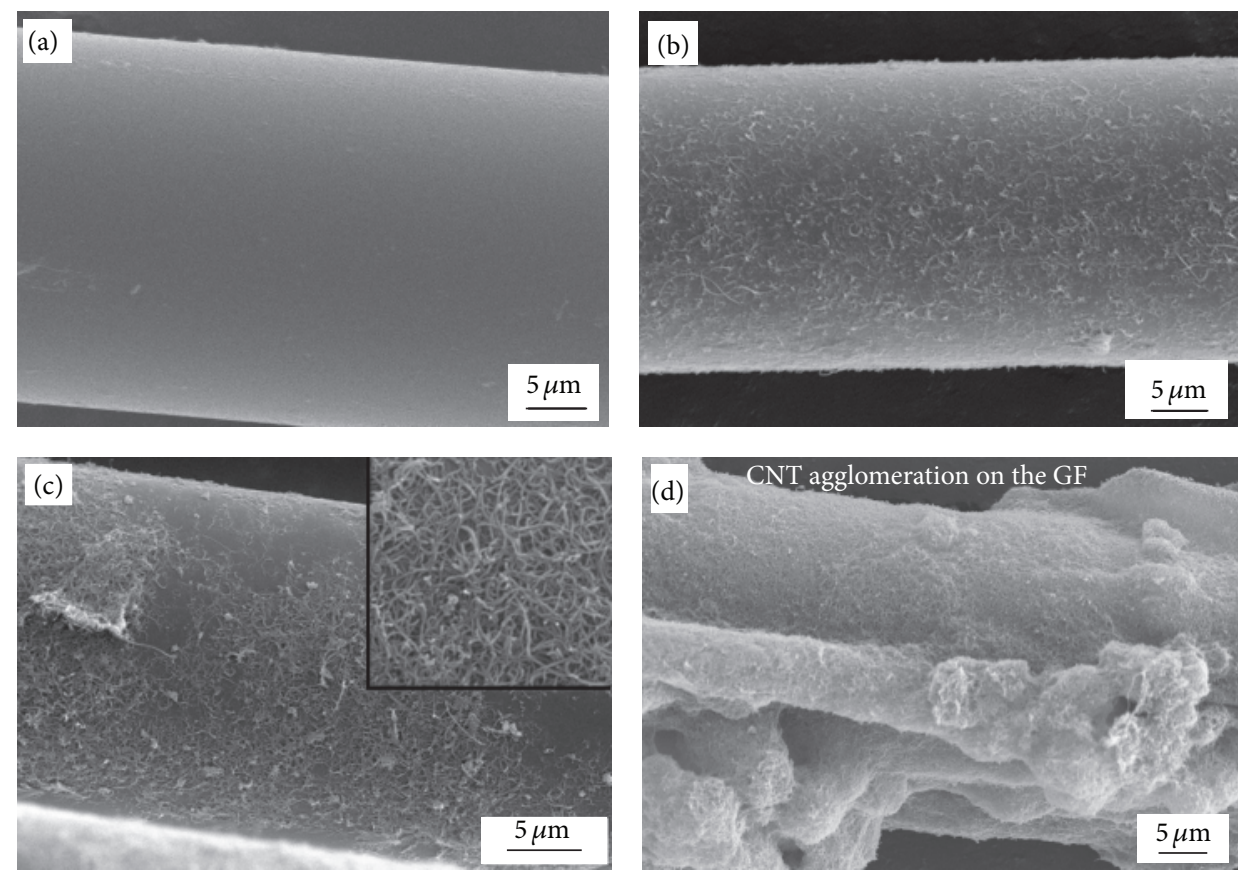

Figure 2: (a) Neat GF and CNT coated GF with different concentrations of CNT suspension, (b) $0.4 \mathrm{mg} / \mathrm{mL},(\mathrm{c}) 1 \mathrm{mg} / \mathrm{mL}$, and (d) $2 \mathrm{mg} / \mathrm{mL}$.
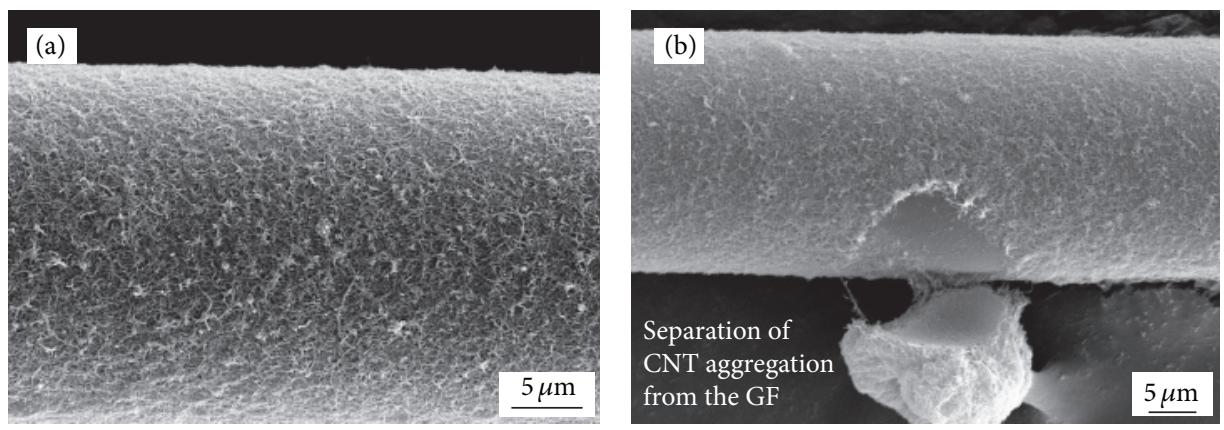

FIGURE 3: CNT coated GF soaked in $1 \mathrm{mg} / \mathrm{mL}$ CNT suspension with soaking time of (a) $60 \mathrm{~min}$ and (b) $180 \mathrm{~min}$.

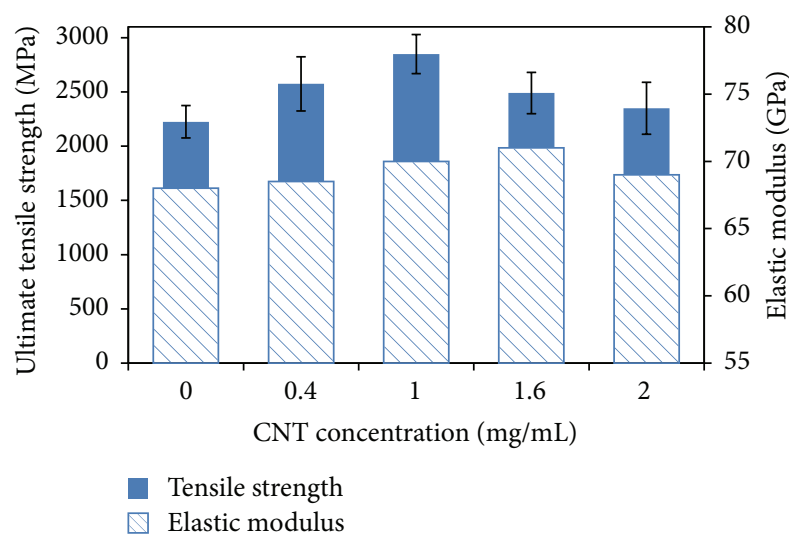

(a)

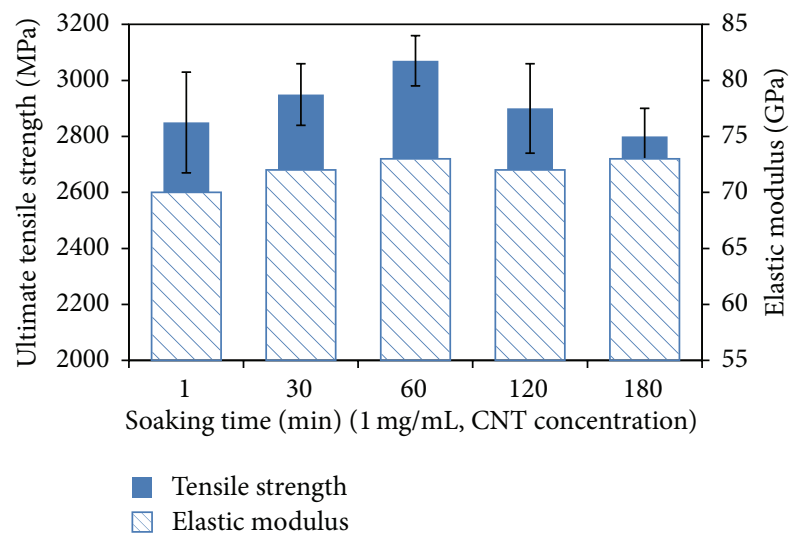

(b)

FIGURE 4: Ultimate tensile strength of CNT coated GF (a) with different CNT concentrations and (b) with different soaking times. 


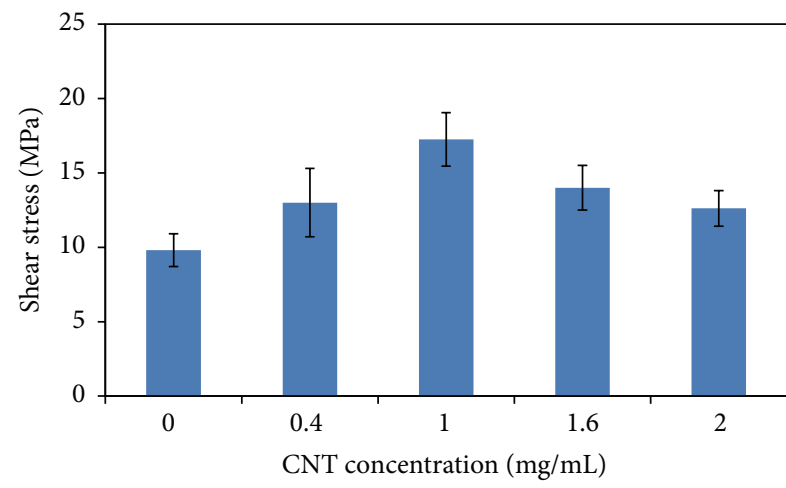

(a)

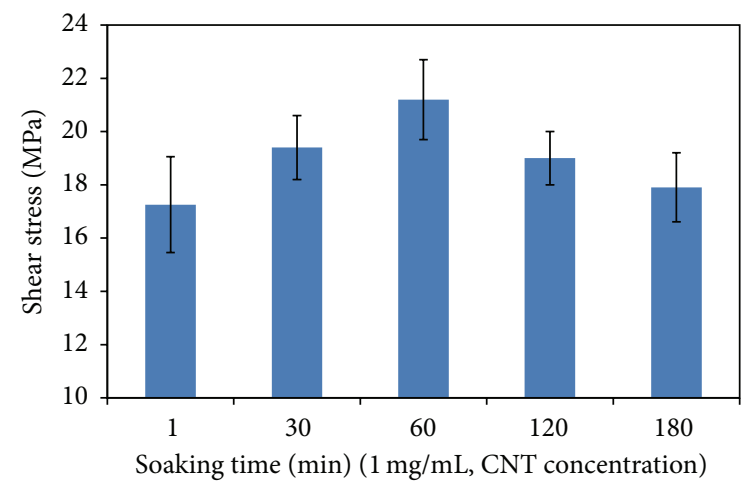

(b)

Figure 5: Interfacial shear stress of CNT coated GF (a) with different suspension concentrations and (b) with different soaking times.

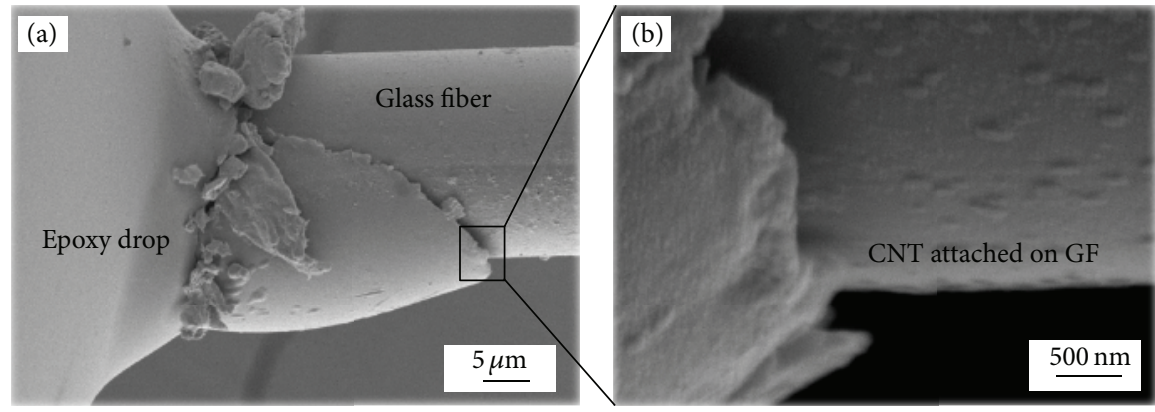

FIGURE 6: SEM images of CNT coated GF after pull-out test.

Appropriate attachment of nanotubes on the surface of GF can repair the defects on the fiber and bridge the crack or flaw as well as hindering their propagation which led to the increase in fiber strength. This achievement is important since CNT cannot grow easily on GF like carbon fiber. Furthermore, growing CNT on carbon fiber often reduces the strength of carbon fiber because of the catalyst interaction with fiber surface $[24,25]$. In the present method, CNT were coated on GF with a simple technique which improved its tensile strength. Considering the magnitude of shear stress between coated GF and epoxy droplet indicates that the improvement of shear stress was achieved with van der Waals bonding [26] as well as mechanical interlocking of nanotubes between the matrix and fiber [27]. In this experiment, chemical treatment was not used in attaching the CNT to the GF. Therefore, it can be inferred that nanotubes can enhance the shear stress of fiber and matrix effectively through mechanical interlocking under optimum coating conditions.

Additional inference of the CNT effects on the mechanical properties of GF can be provided by relating the mechanical properties with the SEM images of coated nanotubes. By increasing the concentration of CNT suspension or soaking time, the coverage of nanotubes on fiber surface increased. Consequently, the matrix-fiber interaction was improved which was afforded by the higher surface area of nanotubes, thus improving the mechanical properties of the coated fiber. However, an optimal coating is necessary since higher concentrations of CNT would cause CNT entanglement. When nanotubes entangle and twist each other, an agglomeration of CNT is created which significantly weakens the matrix-fiber interaction and reduces the stress transfer to individual nanotubes. As shown previously in Figures 2(d) and 3(b), higher than optimum CNT concentrations caused CNT to entangle and create agglomerations on the GF surface. Such areas adhere weaker to the fiber surface and in some regions are obviously separated from the fiber as shown in Figure 3(b). When nanotubes entangle and twist each other, an agglomeration of CNT is created which decline dramatically the stress transfer to individual nanotubes. Such agglomeration bulks form a smooth surface with low interaction to the surrounded fiber or matrix. These configurations were not effective in shear stress between GF and epoxy as well as fiber strength. Hence, CNT coverage is only effective on mechanical properties in optimum condition of nanotubes coating through dip coating technique.

The GF with the optimal coating after pull-out test is shown in Figures 6(a) and 6(b). When a fiber is pulled from a polymer matrix, the tensile force is transmitted to the surrounding matrix on the fiber surface through shear stress. SEM images of the interfacial region of fiber and matrix after fracture can be used to evaluate the effect of CNT coating. Figure 6(a) clearly shows the rough surface of GF on the contact zone of fiber and epoxy drop. The high magnification image of the interface region (Figure 6(b)) demonstrates the adhesion of epoxy on the fiber surface with 
dimensions equal to the CNT coating layer. The coated CNT provide an anchoring mechanism in the interface region, which improves the matrix-fiber interaction. When the GF is pulled, the nanotubes on the interface region undergo both tensile and shear stress followed by being transferred to the epoxy matrix. Therefore, it can be deduced that the morphology of coated fiber indicates that the coating of CNT on GF creates local interlocking between the matrix and fiber which results in the improvement of stress transfer between fiber and matrix.

\section{Conclusions}

A simple dip coating method was presented to graft CNT on GF. Acid treated CNT were dispersed in isopropanol with the addition of Nafion to enhance dispersion. CNT concentration and soaking time of GF in the CNT suspension were investigated to find the optimum coverage of nanotubes. CNT concentration of $1 \mathrm{mg} / \mathrm{mL}$ and $60 \mathrm{~min}$ soaking time was found to provide an optimal coating condition for CNT coated GF. SEM images showed that the CNT coating was homogeneous with complete coverage. Single fiber tensile test and interfacial shear stress were employed to study the effect of CNT coating on the mechanical properties of GFs. Whilst the elastic modulus of coated fibers was approximately unchanged with CNT coating morphology, its ultimate tensile strength increased up to $38 \%$ under optimal CNT coating condition. The interfacial shear stress of optimal CNT coated GF was measured by pull-out test and demonstrated an improvement of up to $116 \%$ compared to neat GF.

\section{Conflict of Interests}

The authors declare that there is no conflict of interests regarding the publication of this paper.

\section{References}

[1] H.-B. Cho, M. T. T. Huynh, T. Nakayama et al., "Densely packed linear assembles of carbon nanotube bundles in polysiloxanebased nanocomposite films," Journal of Nanomaterials, vol. 2013, Article ID 564307, 10 pages, 2013.

[2] Z. Spitalsky, D. Tasis, K. Papagelis, and C. Galiotis, "Carbon nanotube-polymer composites: chemistry, processing, mechanical and electrical properties," Progress in Polymer Science, vol. 35, no. 3, pp. 357-401, 2010.

[3] M. Kumar and Y. Ando, "Chemical vapor deposition of carbon nanotubes: a review on growth mechanism and mass production," Journal of Nanoscience and Nanotechnology, vol. 10, no. 6, pp. 3739-3758, 2010.

[4] P.-N. Wang, T.-H. Hsieh, C.-L. Chiang, and M.-Y. Shen, "Synergetic effects of mechanical properties on graphene nanoplatelet and multiwalled carbon nanotube hybrids reinforced epoxy/carbon fiber composites," Journal of Nanomaterials, vol. 2015, Article ID 838032, 9 pages, 2015.

[5] F.-L. Jin, C.-J. Ma, and S.-J. Park, "Thermal and mechanical interfacial properties of epoxy composites based on functionalized carbon nanotubes," Materials Science and Engineering: A, vol. 528, no. 29-30, pp. 8517-8522, 2011.
[6] R. Rafiee, "Experimental and theoretical investigations on the failure of filament wound GRP pipes," Composites-Part B: Engineering, vol. 45, no. 1, pp. 257-267, 2013.

[7] M. M. Shokrieh and R. Rafiee, "A review of the mechanical properties of isolated carbon nanotubes and carbon nanotube composites," Mechanics of Composite Materials, vol. 46, no. 2, pp. 155-172, 2010.

[8] R. M. Moghadam, "Simulation of impact and post-impact behavior of carbon nanotube reinforced polymer using multiscale finite element modeling," Computational Materials Science, vol. 63, pp. 261-268, 2012.

[9] R. Rafiee, A. Fereidoon, and M. Heidarhaei, "Influence of nonbonded interphase on crack driving force in carbon nanotube reinforced polymer," Computational Materials Science, vol. 56, pp. 25-28, 2012.

[10] M. A. Shazed, A. R. Suraya, S. Rahmanian, and M. A. Mohd Salleh, "Effect of fibre coating and geometry on the tensile properties of hybrid carbon nanotube coated carbon fibre reinforced composite," Materials and Design, vol. 54, pp. 660669, 2014.

[11] S. Rahmanian, K. S. Thean, A. R. Suraya, M. A. Shazed, M. A. Mohd Salleh, and H. M. Yusoff, "Carbon and glass hierarchical fibers: influence of carbon nanotubes on tensile, flexural and impact properties of short fiber reinforced composites," Materials and Design, vol. 43, pp. 10-16, 2013.

[12] S.-J. Park, K.-M. Bae, and M.-K. Seo, "A study on rheological behavior of MWCNTs/epoxy composites," Journal of Industrial and Engineering Chemistry, vol. 16, no. 3, pp. 337-339, 2010.

[13] Q. An, A. N. Rider, and E. T. Thostenson, "Electrophoretic deposition of carbon nanotubes onto carbon-fiber fabric for production of carbon/epoxy composites with improved mechanical properties," Carbon, vol. 50, no. 11, pp. 4130-4143, 2012.

[14] S. Sharma and S. Lakkad, "Effect of CNTs growth on carbon fibers on the tensile strength of CNTs grown carbon fiberreinforced polymer matrix composites," Composites Part A: Applied Science and Manufacturing, vol. 42, no. 1, pp. 8-15, 2011.

[15] A. Shabaneh, S. Girei, P. Arasu et al., "Dynamic response of tapered optical multimode fiber coated with carbon nanotubes for ethanol sensing application," Sensors, vol. 15, no. 5, pp. 10452-10464, 2015.

[16] S. Rahmanian, A. R. Suraya, R. Zahari, and E. S. Zainudin, "Synthesis of vertically aligned carbon nanotubes on carbon fiber," Applied Surface Science, vol. 271, pp. 424-428, 2013.

[17] P. Agnihotri, S. Basu, and K. K. Kar, "Effect of carbon nanotube length and density on the properties of carbon nanotube-coated carbon fiber/polyester composites," Carbon, vol. 49, no. 9, pp. 3098-3106, 2011.

[18] A. J. Rodriguez, M. E. Guzman, C.-S. Lim, and B. Minaie, "Mechanical properties of carbon nanofiber/fiber-reinforced hierarchical polymer composites manufactured with multiscale-reinforcement fabrics," Carbon, vol. 49, no. 3, pp. 937-948, 2011.

[19] J. Zhang, R. Zhuang, J. Liu, E. Mäder, G. Heinrich, and S. Gao, "Functional interphases with multi-walled carbon nanotubes in glass fibre/epoxy composites," Carbon, vol. 48, no. 8, pp. 22732281, 2010.

[20] J. Guo, C. Lu, F. An, and S. He, "Preparation and characterization of carbon nanotubes/carbon fiber hybrid material by ultrasonically assisted electrophoretic deposition," Materials Letters, vol. 66, no. 1, pp. 382-384, 2012. 
[21] Z. Yunusa, M. Hamidon, A. Ismail et al., "Development of a hydrogen gas sensor using a double saw resonator system at room temperature," Sensors, vol. 15, no. 3, pp. 4749-4765, 2015.

[22] S. Rahmanian, A. R. Suraya, M. A. Shazed, R. Zahari, and E. S. Zainudin, "Mechanical characterization of epoxy composite with multiscale reinforcements: carbon nanotubes and short carbon fibers," Materials and Design, vol. 60, pp. 34-40, 2014.

[23] F. An, C. Lu, Y. Li et al., "Preparation and characterization of carbon nanotube-hybridized carbon fiber to reinforce epoxy composite," Materials \& Design, vol. 33, pp. 197-202, 2012.

[24] Q. Zhang, J. Liu, R. Sager, L. Dai, and J. Baur, "Hierarchical composites of carbon nanotubes on carbon fiber: influence of growth condition on fiber tensile properties," Composites Science and Technology, vol. 69, no. 5, pp. 594-601, 2009.

[25] P. Lv, Y.-Y. Feng, P. Zhang, H.-M. Chen, N. Zhao, and W. Feng, "Increasing the interfacial strength in carbon fiber/epoxy composites by controlling the orientation and length of carbon nanotubes grown on the fibers," Carbon, vol. 49, no. 14, pp. 4665-4673, 2011.

[26] G.-P. Wu, Y.-Y. Wang, D.-H. Li et al., "Direct electrochemical attachment of carbon nanotubes to carbon fiber surfaces," Carbon, vol. 49, no. 6, pp. 2152-2155, 2011.

[27] S.-B. Lee, O. Choi, W. Lee et al., "Processing and characterization of multi-scale hybrid composites reinforced with nanoscale carbon reinforcements and carbon fibers," Composites-Part A: Applied Science and Manufacturing, vol. 42, no. 4, pp. 337-344, 2011. 

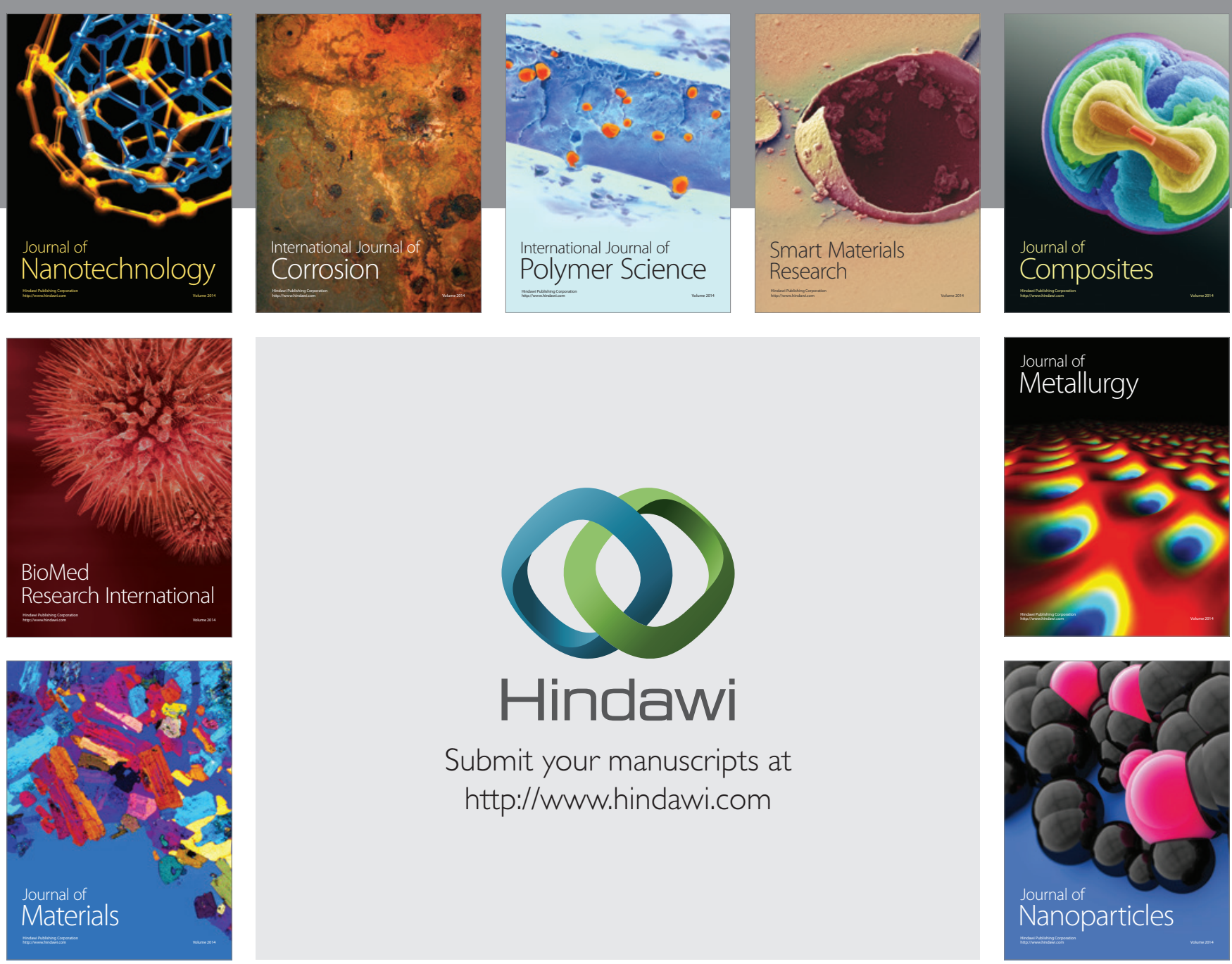

Submit your manuscripts at http://www.hindawi.com
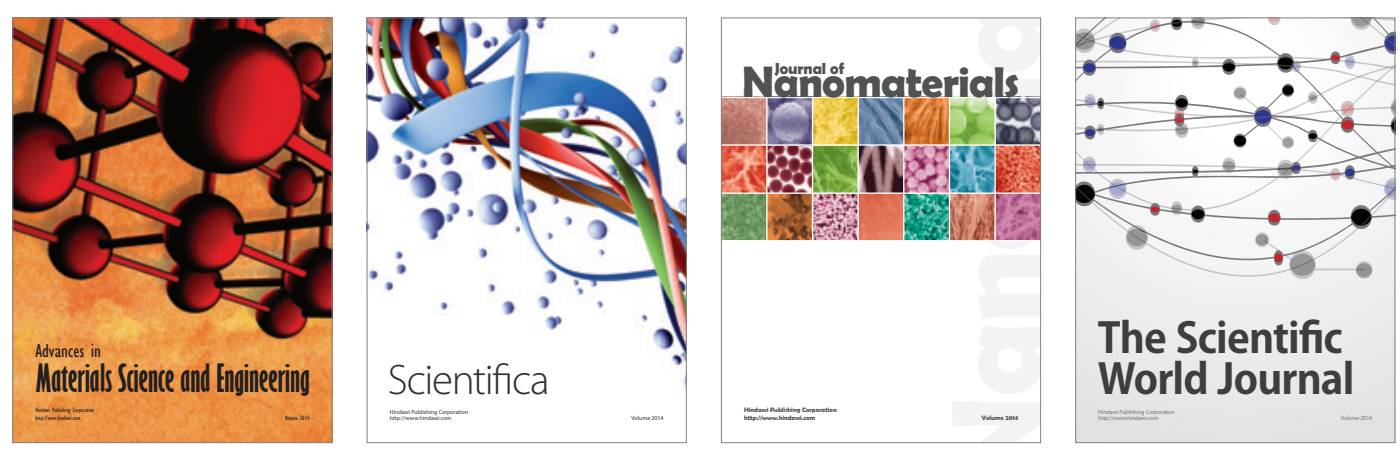

\section{The Scientific World Journal}
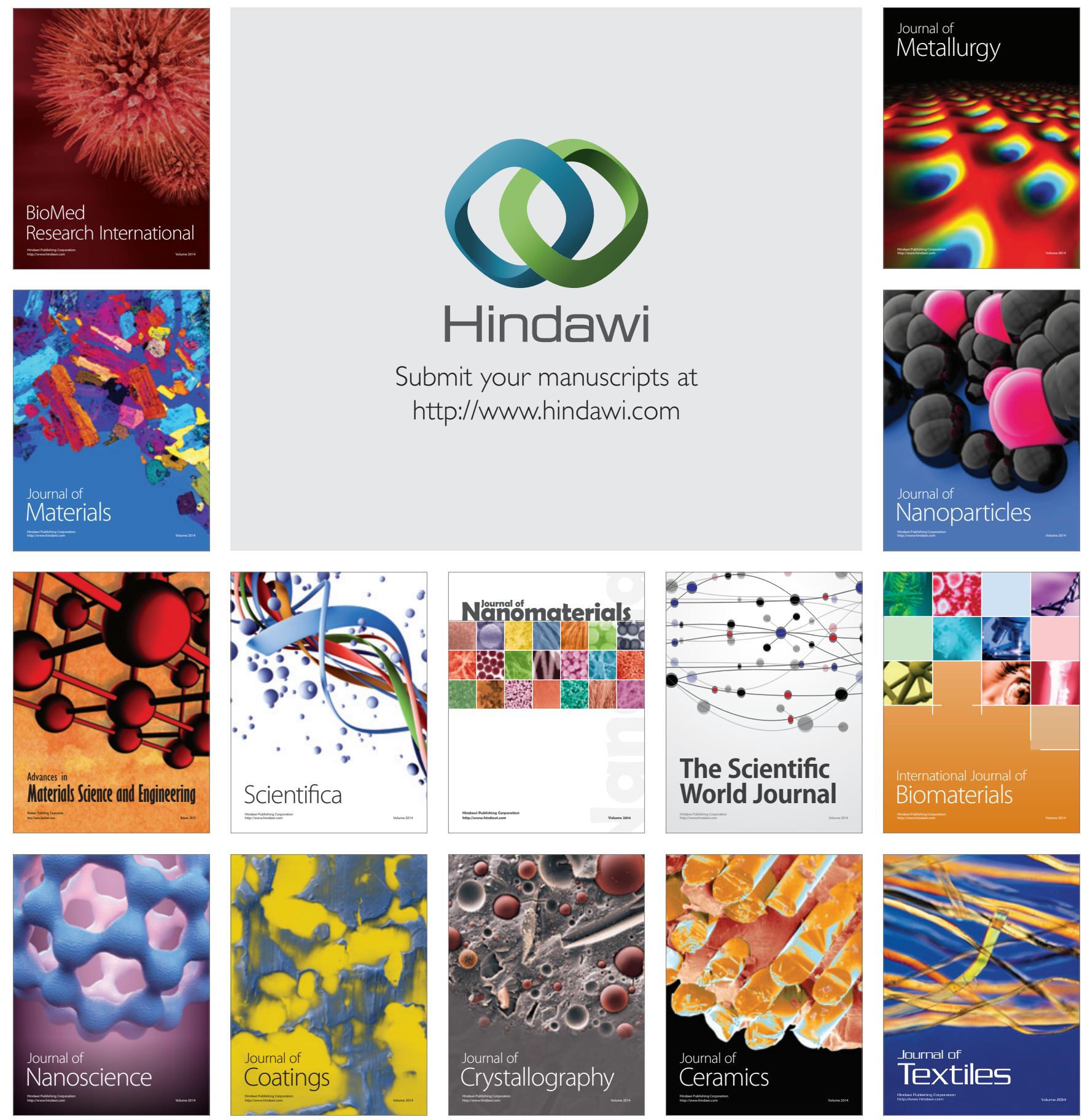